\title{
Fatty acid profiling and comparative evaluation of carcass cut up yield, meat quality traits of Cobb Sasso, commercial broiler and native aseel chicken
}

\author{
Muhammad Hayat Jaspal ${ }^{1 *}$, Sher Ali ${ }^{1}$, Nasir Rajput ${ }^{2}$, Muhammad \\ Naeem $^{2}$, Farah Naz Talpur ${ }^{3}$ and Inamur Rehman ${ }^{1}$ \\ 1. Faculty of Animal Production and Technology, University of Veterinary and Animal Sciences, Lahore- \\ Pakistan \\ 2. Faculty of Animal Husbandry \& Veterinary Sciences, Sindh Agriculture University Tandojam-Pakistan \\ 3. National Center of Analytical Chemistry, University of Sindh. Jamshoro-Pakistan \\ *Corresponding author's email: hayat.jaspal@uvs.edu.pk
}

Citation

Muhammad Hayat Jaspal, Sher Ali, Nasir Rajput, Muhammad Naeem, Farah Naz Talpur and Inamur Rehman. Fatty acid profiling and comparative evaluation of carcass cut up yield, meat quality traits of Cobb Sasso, commercial broiler and native aseel chicken. Pure and Applied Biology. Vol. 9, Issue 1, pp56-65. http://dx.doi.org/10.19045/bspab.2020.90007

\begin{tabular}{|c|c|c|c|}
\hline Received: 01/06/2019 & Revised: 24/08/2019 & Accepted: 05/09/2019 & Online First: 16/09/2019 \\
\hline
\end{tabular}

\section{Abstract}

The present study was conducted to evaluate three different breeds; Cobb Sasso, Commercial Broiler (Cobb 500) and native Aseel (Desi) birds for carcass cut up yield, meat quality, and fatty acid analyses. A total of 48 birds (16 birds per breed, 8 birds per sex) were selected and transported to a slaughtering facility, UVAS, Lahore. Results showed that breed and sex ad significant effects $(p<0.05)$ on carcass cut up yield. Dressing, breast and inner fillets; and the boneless percentages were found higher in broiler birds, while thighs, drumsticks and wings percentages were observed significantly higher in Cobb Sasso birds. The $\mathrm{pH}$ values were significantly higher $(p<0.05)$ at 0,45 min and 2 hours in Broiler and Cobb Sasso birds as compared to Aseel birds. Furthermore, tenderness values were found significantly higher in Aseel birds followed by Cobb Sasso and Broiler birds which indicate the tougher meat in slow-growing birds. $L^{*}$ (lightness) value was observed higher in Broiler birds, while a* (redness) value was found higher in Aseel chicken at 2 and 24 hours after slaughtering. Results of fatty acid analyses showed a significantly $(p<0.05)$ higher level of SFA in Desi and MUFA in Cobb Sasso. No significant difference was observed for PUFA contents between Broiler and Aseel but significantly $(p<0.05)$ lower level was found in Cobb Sasso. In conclusion, a significant difference was found between the breeds as carcass cut up yield was observed higher in Broiler followed by Cobb Sasso than Aseel birds. Better meat quality attributes were found in Broiler and Cobb Sasso birds as compared to Aseel birds. Furthermore, PUFA contents were observed higher in Aseel and Cobb Sasso birds.

Keywords: Aseel; Cobb Sasso; Carcass cut up yield; Fatty acid profile; Tenderness

\section{Introduction}

In Pakistan, the human diet is deficient in animal protein sources, as every person is getting approximately $17 \mathrm{gm}$ of protein against the required $27 \mathrm{gm} \mathrm{/} \mathrm{day} \mathrm{in}$ developed countries [1]. The poultry sector is considered most potent among all animal protein sources due to its fastgrowing potential and better feed conversion ratios. Pakistan has become the 11th largest poultry producer in the world with the production of 1.02 billion Broilers annually. The poultry sector has shown a 
growth of 8-10 percent annually, which reflects its inherent potential [2].

However, the concept of food has undergone a radical transformation, as consumers are more concerned about their health. Poultry producers are influenced by consumer's priorities and paying attention to rear the chicken without antibiotic and other synthetic chemicals. In Pakistan, the poultry birds can be classified into 2 groups i.e. commercial Broiler (Cobb 500 $\&$ Cobb Sasso) and Indigenous (Aseel / Desi). The commercial Broiler (Cobb 500) is reared for $35-40$ days to achieve $2.0 \mathrm{~kg}$ weight [3]. The higher body weight of Cobb (500) could be attributed to the high genetic potential of this breed, however, the Cobb Sasso is the choice for consumers interested in slow-growing, colored chicken. The indigenous Aseel (Desi) birds are oftenly reared for 100 days to achieve $1.0 \mathrm{~kg}$ weight without the use of antibiotics and synthetic chemicals due to better immunity. It has been reported that meat from slow-growing breeds is healthier having low-fat content and a high portion of n-3 PUFA [4]. Indigenous breeds of chickens are also more resilient to adverse environmental conditions like heat stress, high stocking density and metabolic disorders [5]. Chen [6] reported that in China and some bordering countries the market share of indigenous birds represents almost $50 \%$ of all meat-type birds and serves as whole carcass business for premium products.

Moreover, commercial Broilers despite having a fast growth rate and better feed conversion ratio (FCR) has certain challenges like high mortality, antibiotic resistance and less resistance to harsh climatic conditions, which adversely affect the production, meat quality and consumer preference [7]. Conversely, Aseel birds have stronger immunity and can grow in extreme conditions, however due to slow growth rate, poor FCR and low cut up yield i.e. Aseel birds cannot fulfill the meat requirement.
Keeping in view the consumer concerns, poultry industry needs a breed having characteristics like better production rate, immunity and cut up yield. Cobb Sasso (French breed) having modified genetics has been claimed with better livability, production and cut up yield which can fulfill the modern consumer's demand. Cobb Sasso can be reared without antibiotics and due to a relatively slow growth rate than Broiler may impart better flavor. So, the present study was conducted to compare the available Broilers, Aseel and Cobb Sasso breeds in Pakistan; for better carcass cut up yield, meat quality and fatty acids profile.

\section{Materials and methods Experimental birds}

One hundred twenty straight-run birds for each breed, Cobb Sasso and commercial Broiler (Cobb 500) were reared on the littered floor by making replicates. Birds were reared with the similar commercial diets according to their growth phases till the slaughtering age; 35 days (Broiler), 64 days (Cobb Sasso) and 110 days Aseel.

\section{Slaughtering and carcass cut up yield}

A total of 48 birds, 8 males, and 8 females from each breed; were selected for slaughtering to obtain cut up yield (\%). The birds were brought to Meat Processing Unit in the Department of Meat Science and Technology, UVAS, Lahore and after feed deprivation for 8 hours, all the birds were slaughtered, de-feathered according to Halal standards as described in Pakistan Halal Standards (PS3733:2013). Subsequently, the carcasses were eviscerated and the shanks and head were separated.

Carcasses were pre-chilled at $10{ }^{\circ} \mathrm{C}$ for 15 minutes in chilled water and placed in polystyrene trays wrapped with cling film and kept in air chiller at $0-4{ }^{\circ} \mathrm{C}$ for 4 hours before deboning. In the deboning hall, the carcasses were portioned; breast and thigh were weighed. Furthermore, shank, liver, gizzard, heart, intestine, drumstick, major fillet, inner fillet, back, wings, breast boneless yield, leg boneless yield, the total 
boneless yield was measured. Each part was weighed separately and the proportion of specific part for live bird weight was calculated according to CFIA [8].

\section{Meat quality measurements pH}

The $\mathrm{pH}$ was measured from the breast muscle by using calibrated $\mathrm{pH}$ meter (WTW, pH 3210 SET 2, Germany) at an interval of 0,45 minutes and 2 hours after slaughtering. Three readings were taken from different points for each sample by inserting the probe of $\mathrm{pH}$ meter into muscle until it showed a stable value.

\section{Color}

Color values were measured from the breast muscle by using Minolta Calorimeter (Konica Minolta ${ }^{\circledR}$ CR-410, Japan) after 2 and 24 hours of slaughtering. Minolta calorimeter was placed over breast fillet in a way that no external light can influence its readings as described by Vieira and Fernandez, [9]. Lightness $\left(\mathrm{L}^{*}\right)$, Redness $\left(\mathrm{a}^{*}\right)$ Yellowness $\left(b^{*}\right)$, Chroma value (c) and hue angle (h) were the measured parameters of color.

\section{Cooking loss}

Weighed samples from the breast muscle were vacuum-packed individually by Multivac ${ }^{\circledR}$ Baseline P100 vacuum packaging machine is specifically designed to vacuum packaging bags (SR $150 \times 200$, PA/PE 90) and placed in a water bath (Memmert WNB45, Germany) for cooking until attained core temperature of $72-74^{\circ} \mathrm{C}$. Temperature of each sample was measured by placing a food-grade thermometer (TP101, CixiSinco, China) in the center of the sample as described by Liu et al. [10]. After cooking, samples were kept until they attained room temperature [11]. The cooking loss was calculated based on difference between weight before and after cooking as described by Liu et al. [10].

\section{Tenderness}

After cooking, 5 strips of approximately $1 \times 1 \mathrm{~cm}$ were cut parallel to the axis of muscle fibers orientation from each breast sample. Texture analyzer (TA. XT plus ${ }^{\circledR}$ texture analyzer, UK) was used to determine the shear force value in $\mathrm{N} / \mathrm{cm}^{2}$ by placing the strips at a right angle under the V-Slot blade as described by Folch et al. [12].

\section{Fatty acid analysis}

The fatty acid analysis was performed at the National Centre of Excellence in Analytical Chemistry, University of Sindh, Jamshoro. In the first step, the fat was extracted from the meat samples with chloroform and methanol mixture (2:1). And in the second step, the fatty acid methyl esters (FAME) were prepared. A sample of $2.0 \mu \mathrm{L}$ was injected into Gas Chromatograph Flame Ionization Detector (GC-FID) made by Perkin Elmer 8700 having non-polar capillary column DB-1 $(30 \mathrm{~m} \times 0.25 \mathrm{~mm})$ and $0.2 \mu \mathrm{m}$ film thickness. Oxygen-free nitrogen was used as a carrier gas with a flow rate of 3.5 $\mathrm{mL} / \mathrm{min}$. The injection port temperature was $230{ }^{\circ} \mathrm{C}$ and the detector temperature was $260{ }^{\circ} \mathrm{C}$. The oven temperature was ramped to $130{ }^{\circ} \mathrm{C}$ for $3 \mathrm{~min}$ and increased to $180{ }^{\circ} \mathrm{C}$ at $1.5^{\circ} \mathrm{C} / \mathrm{min}$; it was then held at $180{ }^{\circ} \mathrm{C}$ for 3 minutes. Finally, the temperature was increased to $220^{\circ} \mathrm{C}$ at 1 ${ }^{\circ} \mathrm{C} / \mathrm{min}$. All the fatty acids were detected by comparing the retention time with a standard as described by Folch et al. [12].

\section{Statistical analysis}

Collected data were analyzed using factorial ANOVA under a completely randomized design (CRD). Post-hoc analysis was conducted by Fisher's LSD test using SAS 9.1 and $\mathrm{p} \leq 0.05$ was considered significant.

\section{Results and discussion Carcass cut-up yield}

The present study was conducted to evaluate the carcass cut up yield, meat quality and fatty acids profile of three different breeds. Carcass cut up yield is an excellent indicator to determine the efficiency of meat-producing birds. Results showed that dressing, breast fillets and boneless meat yield percentages were found significantly higher in Broiler followed by Cobb Sasso and Aseel birds. Many researchers have also reported 
similar results, as standard commercial Broiler having better carcass yield as compared to indigenous breeds at marketing age [13-15,] In present trail dressing \% was observed as 67\%, 63\% and $58 \%$ for Broiler, Cobb Sasso and Aseel respectively, the results are in agreement with Wang et al. [14] who reported that dressing (\%) above $60 \%$ is considered good. Moreover, dressing \% was found higher in male as compared to the female birds which agreed with the reports of Lopez et al. [16]. Significantly higher thighs, drumsticks and wings (\%) was observed in Cobb Sasso as compared to Aseel and Broiler, however there was no significant difference between Broiler and Aseel birds (Table 1). Nielsen et al. [17] reported similar results by comparing thigh and breast yield of slow-growing and fast-growing chicken. Moreover, thigh and drumstick yield were found higher in male birds as compare the female. Mendes and Santos [18, 19] also reported analogous results by comparing the thigh yield of male and female chicken. However, no significant effect of sex was found on the percentage of wings.

Significantly higher inner fillets yield (\%) was recorded among all three breeds Female showed a significantly higher inner fillets yield as compared to the male birds. Gizzard and shanks yield (\%) were influenced by different genotypes as Desi showed a significantly higher yield when compared to Broiler and Cobb Sasso. Interestingly, gizzard yield was not affected by the sex (Table 1). Similar results were reported by Musa $e t$ la. and Ojedapo et al. [20, 21], when they studied different genotypes. But the shanks yield was found higher in males as compared to female birds and parallel findings were also reported by Munira et al. [22] who observed lower values of shanks yield in female birds.

Liver (\%) was found significantly higher in Aseel and Broiler as compared to Cobb Sasso while liver yield was not affected by sex (Table 1). Similar results were reported by Taha et al. [23], they studied native Egyptian chicken and Canadian breed. However, Enaiat et al. [24] reported the influence of sex on liver yield.

\section{Effect on meat quality}

Meat quality $(\mathrm{pH}$, color, cooking loss \% and tenderness) of poultry products is very important, as it reflects in first (color) and repeated purchase (tenderness) by the consumer. In the present study, significantly higher $\mathrm{pH}$ was observed at 0 hours (immediately after bleeding) in Broiler as compared to Cobb Sasso and Aseel but, there was non-significant difference between Cobb Sasso and Aseel (Table 2). However, sex showed no significant effect on $\mathrm{pH}$ at 0 hours. A similar trend of $\mathrm{pH}$ fall was observed in $\mathrm{pH}$ recorded at 45 minutes. However, $\mathrm{pH}$ value at 2 hours was significantly higher $(p<0.05)$ in males as compared to females and Broiler showed a higher $\mathrm{pH}$ followed Aseel and Cobb Sasso. $\mathrm{pH}$ decline is most important event in the conversion of muscle to meat because, it affects texture, color and water holding capacity [25]. The drastic decline in $\mathrm{pH}$ is associated with more protein denaturation which adversely affects color, water holding capacity and texture [7, 26]. According to Debut et al. [27] active or slow-growing birds are more prone to stress which leads to rapid breast muscle acidification. Many other researchers have also reported a similar trend of lower $\mathrm{pH}$ in slowgrowing birds as compared to fastgrowing birds [28-30]. Selection for better breast meat yield might have impacted on glycogen reserves of breast muscle that might explain the differences between ultimate $\mathrm{pH}$ in fast, medium and slow-growing chicken [31, 32].

Color is also an admirable indicator of meat quality [33, 34]. Myoglobin is the most important protein in the muscles 
which involves the appearance of meat. However, pre-slaughter and postslaughter factors also affect the meat color. Results showed that after 2 hours, color values of Broiler breast meat showed comparatively higher L* (lightness) value as compared to Cobb Sasso and Desi. Redness $\left(a^{*}\right)$ values were observed significantly high in desi birds followed by Cobb Sasso and Broiler. While, yellowness $(b *)$ values were found comparatively high in Cobb Sasso followed by Broiler and Desi birds. There was no significant impact observed on $\mathrm{c}^{*}$ (chroma) and h (hue angle) by any breed. Furthermore, a similar trend was also observed in color values after 24 hours post slaughtering (Table 2). Berri et al. [32] reported similar trend as breeds selected for fast growth showed the paler color of meat (higher L*), which can be explained by the low level of heme pigment which normally increases with age. Moreover, many researchers have also reported that the slowgrowing birds have redder meat in comparison with fast-growing or highperformance birds [31, 32, 35]. According to Lonergan et al. [36], the difference in redness among genotype might be because of the difference in muscle fiber type.

Aseel birds had a significantly higher cooking loss compared to Cobb Sasso and Broiler but, was not affected by sex (Table 2). Although cooking loss percentage in Cobb Sasso (23.88) was higher compared with Broiler (21.28), the margin is reduced. Castellini et al. [37] reported higher cooking loss (\%) in organic or free-range chicken compared to commercial Broiler, because of the low ultimate $\mathrm{pH}$ in organic chicken. Meat tenderness was observed significantly higher in Aseel birds followed by Cobb Sasso and Broiler. Tenderness was not affected by sex. Koohmarai et al. [38] explained it as the higher value of tenderness could be associated with the increase of connective tissues with age.

\section{Fatty acid profile}

The results of fatty acids analysis are presented in the (Table 3). Palmitic acid concentrations were not affected significantly $(\mathrm{p}>0.05)$ by sex and strain. While, stearic acid was observed higher in Aseel birds. Total SFA contents were found significantly higher $(p<0.05)$ in Aseel followed by Broiler and Cobb Sasso, but not effected by sex. Similarly, Wattanachant et al., [29] compared the fatty acids profile of indigenous and Broiler by offering the same diet and reported the higher levels of SFA was present in indigenous birds. In the MUFA contents, palmitoleic acid and oleic acid were found significantly higher in Cobb Sasso, but no significant effect of sex was determined on the MUFA contents in the present study. Total MUFA yield was observed significantly higher in Cobb Sasso followed by Broiler and Aseel birds, respectively. Chae et al. [39] reported that palmitic acid from SFA and oleic acid from MUFA are the main fatty acids found in indigenous and commercial chicken, which are following the present study.

Poultry meat has been considered as good source of PUFA in the human diet $[40,41]$. Total PUFA contents were found higher $(p<0.05)$ in Aseel and Broiler as compared to Cobb Sasso while, it was not influenced by sex. Furthermore, feeding behavior and genetics of different breeds have been found an important factor affecting the fatty acid profile [35]. Marcincakova et al. [41] reported that meat from slow-growing birds has higher PUFA concentration compare to fast-growing birds. Likewise, DHA contents were found higher in Aseel birds. Furthermore, n-3 fatty acids (alinoleic acid, EPA and DHA) concentrations were found lower in Cobb Sasso as compared to Broiler and Desi. 
Table 1. Effect of breed and sex on carcass cut-up yield

\begin{tabular}{|c|c|c|c|c|c|c|c|c|c|}
\hline \multirow{2}{*}{ Parameters (\%) } & \multicolumn{2}{|c|}{ Cobb Sasso } & \multicolumn{2}{|c|}{ Broiler } & \multicolumn{2}{|c|}{ Desi } & \multirow{2}{*}{ Sex } & \multirow{2}{*}{ Strain } & \multirow{2}{*}{ Overall } \\
\hline & M & $\mathbf{F}$ & M & $\mathbf{F}$ & $\mathbf{M}$ & $\mathbf{F}$ & & & \\
\hline Dressing \% & $63.53 \pm 1.84$ & $59.64 \pm 2.64$ & $67.53 \pm 1.92$ & $63.65 \pm 1.48$ & $56.42 \pm 2.78$ & $54.84 \pm 1.44$ & $* * *$ & $* * *$ & $\mathrm{NS}$ \\
\hline Thigh \% & $17.73 \pm 1.09$ & $16.79 \pm 0.53$ & $16.66 \pm 1.80$ & $15.59 \pm 0.93$ & $16.12 \pm 0.80$ & $15.93 \pm 0.94$ & $* *$ & $* * *$ & NS \\
\hline Shank \% & $3.82 \pm 0.34$ & $3.16 \pm 0.19$ & $3.70 \pm 0.28$ & $3.51 \pm 0.29$ & $4.87 \pm 0.33$ & $2.95 \pm 0.23$ & $* * *$ & $* * *$ & $* * *$ \\
\hline Liver \% & $1.84 \pm 0.50$ & $1.63 \pm 0.29$ & $1.95 \pm 0.20$ & $2.17 \pm 0.23$ & $2.20 \pm 0.24$ & $1.87 \pm 0.36$ & NS & $* *$ & $* *$ \\
\hline Gizzard \% & $1.26 \pm 0.31$ & $1.27 \pm 0.12$ & $1.26 \pm 0.16$ & $1.68 \pm 0.34$ & $2.32 \pm 0.44$ & $1.63 \pm 0.30$ & NS & $* * *$ & $* * *$ \\
\hline Drum Stick \% & $10.18 \pm 0.57$ & $9.08 \pm 0.44$ & $8.90 \pm 0.31$ & $8.38 \pm 0.53$ & $9.65 \pm 0.42$ & $8.26 \pm 0.36$ & $* * *$ & $* * *$ & $* *$ \\
\hline Breast Fillet \% & $11.59 \pm 2.08$ & $12.08 \pm 1.17$ & $19.41 \pm 1.23$ & $17.38 \pm 1.31$ & $8.15 \pm 0.94$ & $9.37 \pm 0.89$ & NS & $* * *$ & $* * *$ \\
\hline Inner Fillet \% & $4.13 \pm 0.50$ & $4.72 \pm 0.44$ & $4.30 \pm 0.26$ & $4.65 \pm 0.55$ & $3.01 \pm 0.30$ & $3.30 \pm 0.28$ & $* * *$ & $* * *$ & $\mathrm{NS}$ \\
\hline Wings $\%$ & $5.88 \pm 0.27$ & $6.05 \pm 0.70$ & $5.31 \pm 0.37$ & $5.69 \pm 0.39$ & $5.83 \pm 0.14$ & $5.15 \pm 0.28$ & NS & $* * *$ & $* * *$ \\
\hline Boneless \% & $35.21 \pm 2.90$ & $37.91 \pm 2.39$ & $42.67 \pm 2.15$ & $40.22 \pm 1.72$ & $27.84 \pm 2.05$ & $30.87 \pm 1.82$ & $\mathrm{NS}$ & $* * *$ & $* * *$ \\
\hline Bones \% & $20.16 \pm 1.76$ & $17.28 \pm 1.54$ & $17.63 \pm 1.37$ & $17.56 \pm 1.75$ & $18.93 \pm 1.37$ & $16.84 \pm 0.88$ & $* * *$ & $*$ & $* *$ \\
\hline
\end{tabular}

$* \mathrm{P}<0.05 ; * * \mathrm{P}<0.01 ; * * * \mathrm{P}<0.001 ; \mathrm{ns}$

Different alphabets on means (Mean \pm S.E) showing significant difference $\mathrm{p} \leq 0.05$

Table 2. Effect of breed and sex on meat quality

\begin{tabular}{|c|c|c|c|c|c|c|c|c|c|}
\hline \multirow{2}{*}{ Parameters } & \multicolumn{2}{|c|}{ Cobb Sasso } & \multicolumn{2}{|c|}{ Broiler } & \multicolumn{2}{|c|}{ Desi } & \multirow{2}{*}{ Sex } & \multirow{2}{*}{ Strain } & \multirow{2}{*}{ Overall } \\
\hline & $\mathbf{M}$ & $\mathbf{F}$ & $\mathbf{M}$ & $\mathbf{F}$ & $\mathbf{M}$ & $\mathbf{F}$ & & & \\
\hline $\mathrm{pH}$ at $0 \mathrm{hrs}$ & $5.99 \pm 0.34$ & $5.91 \pm 0.19$ & $6.51 \pm 0.13$ & $6.53 \pm 0.14$ & $5.94 \pm 0.25$ & $6.07 \pm 0.12$ & NS & $* * *$ & NS \\
\hline $\mathrm{pH}$ at $45 \mathrm{Min}$ & $5.82 \pm 0.28$ & $5.90 \pm 0.26$ & $6.38 \pm 0.15$ & $6.36 \pm 0.26$ & $5.87 \pm 0.16$ & $6.05 \pm 0.12$ & NS & $* * *$ & NS \\
\hline $\mathrm{pH}$ at $2 \mathrm{hrs}$ & $5.69 \pm 0.07$ & $5.86 \pm 0.18$ & $6.25 \pm 0.17$ & $6.32 \pm 0.23$ & $5.82 \pm 0.17$ & $6.00 \pm 0.11$ & $* * *$ & $* * *$ & NS \\
\hline $\mathrm{L}^{*}$ at $2 \mathrm{hrs}$ & $59.22 \pm 1.20$ & $59.16 \pm 1.26$ & $60.38 \pm 10.66$ & $60.26 \pm 1.14$ & $56.46 \pm 8.57$ & $56.38 \pm 7.45$ & NS & $* *$ & NS \\
\hline $\mathrm{a}^{*}$ at $2 \mathrm{hrs}$ & $17.53 \pm 0.34$ & $17.49 \pm 0.43$ & $16.04 \pm 7.04$ & $16.00 \pm 0.55$ & $19.64 \pm 5.60$ & $19.56 \pm 4.46$ & NS & $* *$ & NS \\
\hline $\mathrm{b}^{*}$ at $2 \mathrm{hrs}$ & $19.13 \pm 0.81$ & $19.09 \pm 0.76$ & $18.27 \pm 7.40$ & $18.26 \pm 0.74$ & $17.55 \pm 4.17$ & $17.52 \pm 4.13$ & $*$ & $* *$ & $*$ \\
\hline $\mathrm{c}^{*}$ at $2 \mathrm{hrs}$ & $22.01 \pm 0.69$ & $21.97 \pm 0.74$ & $21.14 \pm 7.62$ & $21.10 \pm 0.73$ & $23.91 \pm 5.01$ & $23.87 \pm 3.80$ & $*$ & $\mathrm{NS}$ & $* *$ \\
\hline $\mathrm{h}$ at $2 \mathrm{hrs}$ & $46.82 \pm 8.54$ & $46.78 \pm 8.30$ & $7.37 \pm 79.17$ & $47.33 \pm 11.42$ & $215.44 \pm 72.75$ & $216.77 \pm 70.87$ & $*$ & NS & $*$ \\
\hline $\mathrm{L}^{*}$ at $24 \mathrm{hrs}$ & $58.70 \pm 4.97$ & $58.67 \pm 2.73$ & $60.79+2.75$ & $60.74 \pm 4.47$ & $56.46 \pm 7.04$ & $56.41 \pm 5.71$ & $* *$ & $* *$ & NS \\
\hline $\mathrm{a}^{*}$ at $24 \mathrm{hrs}$ & $17.39 \pm 4.04$ & $17.36 \pm 2.55$ & $17.57 \pm 3.48$ & $17.53 \pm 5.08$ & $20.35 \pm 5.69$ & $20.31 \pm 3.70$ & NS & NS & $* * *$ \\
\hline $\mathrm{b}^{*}$ at $24 \mathrm{hrs}$ & $18.55 \pm 1.83$ & $18.51 \pm 4.14$ & $17.23 \pm 4.74$ & $17.19 \pm 3.36$ & $16.04 \pm 8.49$ & $16.01 \pm 6.81$ & $* *$ & $* * *$ & $* *$ \\
\hline $\mathrm{c}^{*}$ at $24 \mathrm{hrs}$ & $23.74 \pm 2.93$ & $23.73 \pm 3.89$ & $22.14 \pm 3.61$ & $22.10 \pm 4.01$ & $23.43 \pm 9.14$ & $23.40 \pm 7.02$ & NS & $* *$ & $* *$ \\
\hline $\mathrm{h}$ at $24 \mathrm{hrs}$ & $46.72 \pm 3.36$ & $46.66 \pm 2.96$ & $47.68 \pm 4.39$ & $47.66 \pm 4.19$ & $47.98 \pm 4.31$ & $48.02 \pm 3.40$ & $* *$ & $* * *$ & $* *$ \\
\hline Cooking loss $\%$ & $23.90 \pm 5.31$ & $23.85 \pm 1.66$ & $21.30 \pm 3.34$ & $21.27 \pm 3.57$ & $25.74 \pm 1.62$ & $25.78 \pm 4.61$ & NS & NS & NS \\
\hline Tenderness $\left(\mathrm{Kg} / \mathrm{cm}^{2}\right)$ & $17.30 \pm 1.06$ & $17.23 \pm 1.14$ & $10.12 \pm 0.78$ & $10.08 \pm 0.48$ & $23.96 \pm 0.81$ & $23.92 \pm 0.88$ & $* * *$ & $* * *$ & $* *$ \\
\hline
\end{tabular}

$* \mathrm{P}<0.05 ; * * \mathrm{P}<0.01 ; * * * \mathrm{P}<0.001 ; \mathrm{ns}$

Different alphabets on means (Mean \pm S.E) showing significant difference $p<0.05$ 
Table 3. Effect of breed and sex on fatty acids profile

\begin{tabular}{|c|c|c|c|c|c|c|c|c|c|}
\hline \multirow{2}{*}{ Parameters } & \multicolumn{2}{|c|}{ Cobb Sasso } & \multicolumn{2}{|c|}{ Broiler } & \multicolumn{2}{|c|}{ Desi } & \multirow{2}{*}{ Sex } & \multirow{2}{*}{ Strain } & \multirow{2}{*}{ Overall } \\
\hline & $\mathbf{M}$ & $\mathbf{F}$ & $\mathbf{M}$ & $\mathbf{F}$ & $\mathbf{M}$ & $\mathbf{F}$ & & & \\
\hline Lauric acid & 0.00 & 0.00 & $0.74 \pm 0.70$ & $0.51 \pm 0.49$ & $0.38 \pm 0.43$ & 0.00 & NS & $* *$ & NS \\
\hline Myristic acid & $0.60 \pm 0.24$ & $0.81 \pm 0.45$ & $1.44 \pm 1.39$ & $0.76 \pm 0.30$ & $0.88 \pm 0.23$ & $0.96 \pm 0.08$ & NS & NS & NS \\
\hline Palmitic acid & $24.71 \pm 0.84$ & $24.90 \pm 2.08$ & $24.78 \pm 1.91$ & $26.79 \pm 2.76$ & $26.85 \pm 3.91$ & $26.77 \pm 0.57$ & NS & NS & NS \\
\hline Stearic acid & $6.22 \pm 1.24$ & $5.81 \pm 1.47$ & $7.48 \pm 0.96$ & $7.244 \pm 1.86$ & $12.06 \pm 4.00$ & $9.49 \pm 0.76$ & NS & $* *$ & NS \\
\hline Arachidic acid & 0.00 & $1.88 \pm 2.59$ & $0.41 \pm 0.05$ & $0.97 \pm 0.62$ & $1.56 \pm 2.73$ & 0.00 & NS & NS & NS \\
\hline${ }^{1}$ SFA & $31.53 \pm 1.39$ & $33.15 \pm 2.88$ & $34.58 \pm 1.09$ & $36.33 \pm 3.37$ & $39.73 \pm 1.38$ & $39.20 \pm 0.53$ & NS & $* * *$ & NS \\
\hline Myristoleic acid & 0.00 & 0.00 & $2.65 \pm 1.81$ & $0.84 \pm 1.23$ & 0.00 & 0.00 & NS & $* * *$ & NS \\
\hline Palmitoleic acid & $4.11 \pm 0.32$ & $3.94 \pm 2.01$ & $3.03 \pm 1.37$ & $1.44 \pm 1.51$ & $2.02 \pm 1.20$ & $2.58 \pm 1,62$ & NS & $* *$ & NS \\
\hline Oleic acid & $34.24 \pm 8.79$ & $26.21 \pm 6.80$ & $12.04 \pm 1.49$ & $9.24 \pm 1.37$ & $10.94 \pm 2.68$ & $8.84 \pm 0.66$ & NS & $* * *$ & NS \\
\hline Paullinic acid & $0.73 \pm 0.27$ & $2.15 \pm 2.80$ & $4.38 \pm 4.16$ & $4.74 \pm 2.85$ & $1.32 \pm 0.79$ & $0.56 \pm 0.32$ & NS & $* *$ & NS \\
\hline${ }^{2}$ MUFA & $39.08 \pm 8.76$ & $32.30 \pm 4.90$ & $19.58 \pm 1.11$ & $18.38 \pm 1.06$ & $14.18 \pm 0.94$ & $12.08 \pm 1.07$ & NS & $* * *$ & NS \\
\hline Linoleic acid & $19.15 \pm 3.55$ & $17.41 \pm 7.90$ & $3.87 \pm 2.64$ & $3.66 \pm 1.65$ & $4.07 \pm 0.97$ & $1.60 \pm 0.63$ & NS & $* * *$ & NS \\
\hline$\alpha$-linolenic acid & $3.73 \pm 3.73$ & $5.43 \pm 1.76$ & $2.48 \pm 0.41$ & $2.82 \pm 1.77$ & $2.50 \pm 2.22$ & $2.10 \pm 0.60$ & NS & NS & NS \\
\hline Eicosadienoic acid & $0.67 \pm 0.15$ & $0.55 \pm 0.21$ & $4.21 \pm 0.37$ & $1.83 \pm 3.13$ & $3.88 \pm 6.37$ & $1.69 \pm 0.34$ & NS & NS & NS \\
\hline Eicosastrienoic acid & 0.00 & 0.00 & $3.10 \pm 0.55$ & $0.71 \pm 1.43$ & $0.28 \pm 0.55$ & $2.66 \pm 0.14$ & NS & $* * *$ & $* * *$ \\
\hline Arachidonic acid & $0.75 \pm 0.09$ & $0.67 \pm 0.19$ & $7.07 \pm 1.04$ & $6.74 \pm 1.53$ & $7.95 \pm 3.72$ & $6.17 \pm 0.80$ & NS & $* * *$ & NS \\
\hline Eicosapentaenoic acid & $1.14 \pm 0.74$ & $0.87 \pm 0.39$ & $0.53 \pm 0.91$ & 0.00 & 0.00 & 0.00 & NS & $* *$ & NS \\
\hline Adrenic acid & 0.00 & 0.00 & $2.17 \pm 0.33$ & $13.71 \pm 7.43$ & $0.93 \pm 1.32$ & $3.20 \pm 0.22$ & $* *$ & $* * *$ & $* *$ \\
\hline Docosapentaenoic acid & $1.27 \pm 1.45$ & $3.28 \pm 4.12$ & $14.95 \pm 3.59$ & $3.13 \pm 5.10$ & $16.67 \pm 3.22$ & $16.67 \pm 3.23$ & NS & $* * *$ & $* *$ \\
\hline Docosahexaenoic acid & $0.85 \pm 0.65$ & $4.41 \pm 5.34$ & $5.72 \pm 1.02$ & $11.59 \pm 4.94$ & $8.17 \pm 3.39$ & $10.92 \pm 1.13$ & $* *$ & $* *$ & NS \\
\hline${ }^{3}$ PUFA & $27.56 \pm 9.75$ & $32.61 \pm 5.94$ & $44.13 \pm 0.38$ & $44.19 \pm 3.15$ & $44.44 \pm 2.19$ & $46.85 \pm 0.69$ & NS & $* * *$ & NS \\
\hline Total Fatty acids (Detected) & $98.17 \pm 0.16$ & $98.07 \pm 0.47$ & $98.29 \pm 0.54$ & $98.97 \pm 0.95$ & $98.17 \pm 0.96$ & $97.97 \pm 0.84$ & NS & NS & NS \\
\hline PUFA/SFA & $0.88 \pm 0.35$ & $0.99 \pm 0.21$ & $1.28 \pm 0.03$ & $1.23 \pm 0.22$ & $1.12 \pm 0.09$ & $1.20 \pm 0.03$ & NS & $*$ & NS \\
\hline $\mathrm{N} 3 / \mathrm{n} 6$ ratio & $0.32 \pm 0.23$ & $1.34 \pm 1.85$ & $1.94 \pm 0.71$ & $2.33 \pm 0.83$ & $2.47 \pm 0.92$ & $3.35 \pm 0.41$ & NS & $*$ & NS \\
\hline
\end{tabular}

$* \mathrm{P}<0.05 ; * * \mathrm{P}<0.01 ; * * * \mathrm{P}<0.001 ; \mathrm{ns} ;{ }^{1}$ Saturated Fatty acids $\cdot{ }^{2}$ Mono-unsaturated Fatty acids ${ }^{3}$ Poly-unsaturated Fatty acids

Different alphabets on means (Mean \pm S.E) showing significant difference $p \leq 0.05$ 


\section{Conclusion}

Based on the findings of the present study, it can be concluded that males having higher carcass cut-up yield, so separate rearing can increase the yield. Cobb Sasso birds showed higher carcass cut up yield than native Aseel birds. Similarly, a slow rate of $\mathrm{pH}$ fall was observed in Broiler and Cobb Sasso when compared to Aseel birds, which minimizes the incidence of PSE (pale soft exudative) and also reflects in better meat quality as low water loss. Tenderness values of Broiler and Cobb Sasso were also found superior than to Aseel birds and were not affected by sex. Furthermore, PUFA concentrations were observed higher in Desi and Broiler as compare to Cobb Sasso.

\section{Authors' contributions}

Conceived and designed the experiments: MH Jaspal \& S Ali, Performed the experiments: I Rehman, Analyzed the data: M Naeem, N Rajput \& I Rehman, Contributed reagents/ materials/ analysis tools: FN Talpur, Wrote the paper: $\mathrm{N}$ Rajput, S Ali \& M Naeem.

\section{Acknowledgments}

This research was financially supported by the Department of Meat Science and Technology, University of Veterinary \& Animal Sciences, Lahore, Pakistan.

\section{References}

1. Pakistan Poultry Association (2018). Eliminating Protein Deficiency. Research and development. Web.https://pakistanpoultrycentral.pk I researchand development I eliminating protein deficiency Pakistan poultry-association/ . Accessed on April 28, 2018.

2. Government of Pakistan, GOP (2016). Economy Survey of Pakistan. In Chapter 2. Ministry of Finance, Agriculture, Government of Pakistan.

3. Government of Pakistan, GOP (2017) Economic Survey of Pakistan, Ministry of Finance, Agriculture, Government of Pakistan.
4. Sirri F, Castellini C, Bianchi M, Petracci M, Meluzzi A \& Franchini A (2011). Effect of fast, medium and slow-growing stains on met quality of chickens reared under the organic farming method. Anim 5: 312-319.

5. Fanatico AC, Pillai PB, Hester PY, Falcone C, Mench JA, Owens CM \& Emmert JL (2008). Performance, Livability, and Carcass Yield of Slow- and Fast-Growing Chicken Genotypes Fed Low-Nutrient or Standard Diets and Raised Indoors or with Outdoor Access, Poul Sci 87: 1012-1021.

6. Chen JL, Zhao GP, Zheng MQ, Wen J \& Yang N (2008). Estimation of genetic parameters for contents of intramuscular fat and inosine-5'monophosphate and carcass traits in Chinese Beijing-You chickens. Poul Sci 87: 1098-1104.

7. Mehaffey JM, Pradhan SP, Meullenet JF, Emmert JL, McKee \& Owens CM (2006). Meat Quality Evaluation of Minimally Aged Broiler Breast Fillets from Five Commercial Genetic Strains. Poul Sci 85: 902908.

8. CFIA (1999). Meat Cuts Manual. Canadian Food Inspection Agency, Ottawa. http://inspection.gc.ca/eng/12979645 99443/1297965645317

9. Vieira C \& Fernandez A (2014). Effect of aging time on suckling lamb meat quality resulting from different carcass chilling regimes. Meat Sci 96(2): 682-687.

10. Liu Y, Mao Y, Zhang Y, Liang R, Wang R, Zhu L, Meng X \& Luo X (2015). Pre-rigor temperature control of Chinese yellow cattle carcasses to $12-18{ }^{0} \mathrm{C}$ during chilling improves beef tenderness. Meat Sci 100: 139144.

11. Shanks B, Wulf D, Reuter B \& Maddock R (2002). Increasing tenderness of beef round and sirloin muscles through pre-rigor skeletal 
separations. Anim Sci J 80(1): 123128.

12. Folch F, Lees M \& Sloane-Stanley GH (1957). A simple method for the isolation and purification of total lipids from animal tissues. $J$ Biol Chem 226: 497-509.

13. Ding HB, Xu RJ \& Chen GA (2000). Comparison of meat quality between China local chickens and Broilers. Anim Hus Vet Med 32: 16-18.

14. Wang XQ, Dai FW, Zhang CM, Tan HZ, Zou SG \& Feng DY (2006). Comparison of partial meat quality indices of $\mathrm{AA}$ and Lingnanhuang yellow-feathered Broiler chicken. Hua Nan Nong Ye Da Xue Xue Bao, 27: 76-80.

15. Lopez KP, Schilling MW \& Corzo A (2011). Broiler genetic strain and sex effects on meat characteristics. Poul Sci 90: 1105-1111.

16. Nielsen BL, Thomsen MG, PS \& Young JF (2003). Feed and strain effects on the use of outdoor areas by Broilers. Brit Poul Sci 44(2): 161169.

17. Mendes AA, Moreuira J \& Oliveira EG (2004). Effect of dietary energy on performance, carcass yield and abdominal fat of Broiler chickens. Revista Brazil Zootech, 33(6): 23002307.

18. Santos AL, Sakomura ER, Freitas ER, Barbosa NAA, Mendonca MO \& Carrilho ENVM (2004). Carcass yield and meat quality of three strains of Broiler chicken. XXII World Poultry Congress, WPSA Turkish Branch, Jun 8-13, Istanbul, Turkey.

19. Musa HH, Chen GH, Cheng JH, Li BC \& Mekki DM (2006). Study of carcass characteristics of chicken breeds raised under the intensive condition. Int J Poul Sci 5(6): 530533.

20. Ojedapo LO, Akinokun O, Adedeji TA, Olayeni TB, Ameen SA \& Amao SA (2008). Effect of strain and sex on carcass characteristics of three commercial Broilers reared in deep litter system in the derived savanna area of Nigeria. World J Agri Sci 4(4): 487-491.

21. Munira KN, Uddin MJ, Faruque S, Parvez MS, Miah MY \& Siddiqui MSI (2006). Comparative study on carcass characteristics of different genetic groups of spent hen in Bangladesh. Int J Poul Sci 5(2): 178180.

22. Taha AE, El-Ghany FAA \& Sharaf MM (2010). Strain and sex effects on productive and slaughter performance of developed local Egyptian and Canadian chicken strains. Egypt Poul Sci 30(4): 1059-1072.

23. Enaiat MM, Amina AS \& Eman MA (2010). A comparative study of productive and physiological performance between two local strains of chicks. Egypt Poul Sci 30(I): 297-316.

24. Aberle ED, Forrest JC, Gerrard DE \& Mills EW (2001). Principles of Meat Science. 4th Ed. Kendall/Hunt Publ. Co. Dubuque, IA.

25. Schilling MW, Radhakrishnan V, Thaxton YV \& Christensen K (2008). The effects of Broiler catching method on breast meat quality. Meat Sci 79: 163-171.

26. Debut M, Berri C, Arnould C, Guemené D, Santé-Lhoutellier V, Sellier N, Baéza E, Jehl N, Jégo Y, Beaumont $\mathrm{C} \&$ Bihan-Duval ELe (2005). Behavioral and physiological responses of three chicken breeds to pre-slaughter shackling and acute heat stress, Brit Poul Sci 46(5): 527535.

27. Quentin M, Bouvarelb I, Berri C, Bihan-Duval ELe, Baeza E, Jego Y \& Picard M (2003). Growth, carcass composition and meat quality response to dietary concentrations in fast, medium and slow-growing Commercial Broilers. Anim Res 52: 65-77. 
28. Wattanachant S, Benjakul S \& Ledward DA (2004). Composition, Color, and Texture of Thai Indigenous and Broiler Chicken Muscles. Poult Sci 83: 123-128.

29. Berri C, Debut M, Sante-Lhoutellier V, Arnould C, Boutten B, Sellier N, Baeza E, Jehl N, Jego Y, Duclos MJ \& Bihan-Duval ELe (2005). Variations in chicken breast meat quality: implications of struggle and muscle glycogen content at death. Brit Poul Sci 46(5): 572-579.

30. Bihan-Duval ELe, Millet N, Remignon H (1999). Broiler meat quality: effect of selection for increased carcass quality and estimates of genetic parameters. Poult Sci 78: 822-826.

31. Berri C, Wacrenier $\mathrm{N}$, Millet $\mathrm{N}$ \& Bihan-Duval ELe (2001). Effect of Selection for Improved Body Composition on Muscle and Meat Characteristics of Broilers from Experimental and Commercial Lines. Poult Sci 80: 833-838.

32. Owens CM, Hirschler EM, McKee, Martinez-Dawson R \& Sams AR (2000). The characterization and incidence of pale, soft, exudative turkey meat in a commercial plant. Poult Sci 79: 553-558.

33. Woelfel RL, Owens CM, Hirschler EM, Martinez-Dawson R \& Sams AR (2002). The characterization and incidence of pale, soft, and exudative Broiler meat in a commercial processing plant. Poul Sci 81: 579584.

34. Debut M, Berri C, Baeza E, Sellier N, Arnould C, Guemene D, Jehl N, Boutten B, Jego Y, Beaumont C \& Bihan-Duval ELe (2003). Variation of chicken technological meat quality in relation to genotype and preslaughter stress conditions. Poul Sci 82: 1829-1838.

35. Lonergan SM, Deeb N, Fedler CA \& Lamont SJ (2003). Breast meat quality and composition in unique chicken populations. Poul Sci 82: 1990-1994.

36. Castellini C, Mugnai C, Dal Bosco A (2002). Meat quality of three chicken genotypes reared according to the organic system. Ital J Food Sci 14: 401-412.

37. Koohmaraie M, Kent MP, Shackelford SD, Veiseth E, Wheeler TL (2002). Meat tenderness and muscle growth: Is there any relationship. Meat Sci 62: 345-352.

38. Chae HS, Kim SH, Kim BY, Yoo YM, Kim JH, Ahn CN, Lee JM, Kim YK \& Choi YI (2002). Changes of the fatty acid, amino acids and collagen contents in domestic Broiler chickens of different marketing standard. Korean J Food Sci Anim Resource, 22: 1-7.

39. Howe P, Meyer B, Record S, Baghurst K (2006). Dietary intake of long-chain $\omega-3$ polyunsaturated fatty acids: contribution of meat sources. Nutrition 22: 47-53.

40. Ponte PIP, Alves SP, Bessa RJB, Ferreira LMA, Gama LT, Bras JLA, Fontes CMGA \& Prates JAM (2008). Influence of Pasture Intake on the Fatty Acid Composition, and Cholesterol, Tocopherols, and Tocotrienols Content in Meat from Free-Range Broilers Poul Sci 87: 8088.

41. Marcincakova D, Certik M, Marcincak S, Popelka P, Simkova J, Klempova T, Petrovic V, Tuckova M \& Baca M (2011). Effect of dietary supplementation of Melissa officinalis and combination of Achillamillefolium and Crataegusoxyacantha on Broiler growth performance, fatty acid composition and lipid oxidation of chicken meat. Ital J Anim Sci 10(43): 165-170. 